\title{
COVID-19 y Florence Nightingale
}

COVID-19 and Florence Nightingale

COVID-19 e Florence Nightingale

\section{Mercedes Neto ${ }^{1}$; Fernando Porto ${ }^{2}$; Hugo Alberto Neves ${ }^{3}$; Tatiana de Oliveira Gomes $^{4}$ \& Luiza Mara Correia ${ }^{5}$}

${ }^{1}$ Faculdade de Enfermagem da Universidade do Estado do Rio de Janeiro. Brasil. Correo electrónico: mercedesneto@yahoo.com.br Orcid: http://orcid.org/0000-0001-7529-9535

${ }^{2}$ Universidade Federal do Estado do Rio de Janeiro. Brasil. Correo electrónico: ramosporto@openlink.com.br Orcid: http://orcid.org/0000-0002-2880-724X

${ }^{3}$ Universidade Federal do Estado do Rio de Janeiro. Brasil. Correo electrónico: hugoal.neves2@hotmail.com Orcid: http://orcid.org/0000-0002-0859-4654

${ }^{4}$ Fundação Oswaldo Cruz. Correo electrónico: tatiogomes83@gmail.com Orcid: http://orcid.org/0000-0003-1147-1070

${ }^{5}$ Universidade do Estado do Rio de Janeiro. Brasil. Correo electrónico: luimarauerj@gmail.com Orcid: http://orcid.org/0000-0002-4660-2416

Correspondencia: Faculdade de Enfermagem da Universidade do Estado do Rio de Janeiro. Brasil Correo electrónico de contacto: mercedesneto@yahoo.com.br

Cómo citar este artículo: Neto, M., Porto, F., Neves, H.A., Oliveira-Gomes, T., \& Correia, L.M. (2021). COVID-19 y Florence Nightingale. Cultura de los Cuidados. (Edición digital). 25 ( No esp.). Recuperado de http://dx.doi.org/10.14198/cuid.2021.esp.10

Recibido:25/11/2020 Aceptado: 12/02/2021

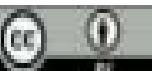


Congreso Virtual Comemoriación del

Bicentenario del Nascimento de Florence Nightingale(1820-2020), no período de 25 a 27 de maio de 2020, em Santa Cruz de

\section{RESUMEN}

Reflexión reconfigurada de la conferencia presentada y titulada "Lecciones de Florence Nightingale en tiempos del Covid-19” en el I Congreso Virtual Comemoriación del Bicentenario del Nascimento de Florence Nightingale (18202020), del 25 al 27 de mayo de 2020, en Santa Cruz de Tenerife (España). Por tanto, estas son algunas lecciones dejadas por el líder de la enfermería moderna aplicada en el momento actual de la pandemia Covid-19, cuando actitudes posiblemente desatendidas por las autoridades públicas, privadas $\mathrm{y}$ sanitarias quedaron en un segundo $\mathrm{y} / \mathrm{o}$ tercer plan. de un brote local a una pandemia. Palabras-clave: COVID-19; Historia de la enfermería; Cuidado; Enfermería.

\section{ABSTRACT}

Reconfigured reflection of the lecture presented and entitled "Lessons from Florence Nightingale in times of Covid-19" at the I Congreso Virtual Comemoriación del Bicentenario del Nascimento by Florence Nightingale (1820-2020), from 25 to 27 May 2020, in Santa Cruz de Tenerife (Spain). Therefore, these are some lessons left by the leader of modern nursing applied in the present time of the Covid-19 pandemic, when attitudes possibly neglected by public, private and health authorities were left to second and / or third plans from a local outbreak to a pandemic. Keywords: COVID-19; History of Nursing; Care; Nursing.

\section{RESUMO}

Reflexão reconfigurada da palestra apresentada e intitulada "Lições de Florence Nightingale em tempos da Covid-19" no I
Tenerife (Espanha). Assim sendo, trata-se de algumas lições deixadas pela líder da enfermagem moderna aplicadas no tempo presente da pandemia da Covid-19, quando atitudes, possivelmente, negligenciadas pela vida pública, privada e das autoridades sanitárias foram deixadas para segundos e/ou terceiros planos, passando de surto local para pandemia.

Palavras-chave: COVID-19; História da Enfermagem; Cuidado; Enfermagem.

\section{CONSIDERAÇÕES INICIAIS}

Florence Nightingale de família nobre, nasceu em 1820, na cidade de Florence/Itália e faleceu em 1910, na Inglaterra. Para conduzir a reflexão da situação da pandemia de COVID-19 e as lições deixadas por Florence Nightingale tivemos por baliza destinadas as lições deixadas do passado o período de 1856-1858 referente a guerra da Crimeia para diálogo sobre o período pandêmico que na atualidade atravessamos com as ditas "novas" etiquetas sociais com a lavagem das mãos e higiene no sentido do ambiente, por exemplo. Isso nos remeteu a concepção de determinada mudança na vida sociocultural entendida como ruptura, cesura ou a algum momento inaugural de uma determinada prática, costume, concepção, evento (Albuquerque Júnior, 2007).

\section{DESENVOLVIMENTO DO TEMA Guerra da Crimeia e contexto vitoriano}

Em síntese, Florence, na Guerra da Crimeia (1854-1856), no período de 18551856, liderou um grupo de 38 mulheres e ficou conhecida, como Dama da Lâmpada por percorrer às noites frias nas enfermarias 
em Scutari. O cenário de sofrimento e miséria era fato. Havia soldados deitados em camas de baixa qualidade e até mesmo no chão, isto sem levar em consideração a baixa ventilação e de saneamento. O sistema de água era precário, ao ponto de se encontrar obstruído por animais mortos e excrementos humanos e mais com vazamento para os tanques de água (Porto et al., 2020).

Florence mediante aquele cenário desagradável reconfigurou os aspectos higiênicos e de alimentação. Registrou as condições encontradas e àquelas adotadas para tempos depois se debruçar e dar origem ao Diagrama da Rosa no sentido de evidenciar as taxas de mortalidades - antes e depois -, quando foi possível mostrar a redução de mortes, Em outras palavras, de 18 mil mortes, 16 mil partiram por doenças infecciosas (Porto et al., 2020).

No período da guerra da Crimeia, na Inglaterra, as condições sanitárias eram a desejar ao ponto de do escritor Charles Dickens escrever um romance, publicado na modalidade de série (1843-1844. Na obra, a personagem denominada Sairey Gamp que apresenta aos leitores o estereótipo de enfermeira idosa, desleixada e bêbada, bem como o clima da prestação de cuidados, considerado como uma das formas de sustento, considerando a condição feminina na era vitoriana com seus hábitos e costumes. Isto de certa forma explica a deferência da Rainha Victoria ao homenagear Florence Nightingale com uma medalha de honra ao mérito pelos feitos no conflito bélico e suas intervenções na mudança das instituições de saúde inglesa, bem como na política de saúde pública e criação de uma escola para enfermeiras anexa ao Hospital S. Thomas. Isto posto, Florence foi produto de contexto vitoriano requintado, mas também como diversas mazelas.

Florence Nightingale: 200 anos de seu nacimento
A COVID-19, foi notificada em 22 de janeiro de 2020 pela Organização Mundial de Saúde, quando em 2019, um novo subtipo viral foi identificado na China. Ela foi declarada pela Organização Mundial de Saúde, em 11 de março de 2020, tendo por dados até a primeira semana de abril de 2020: 1.210 .956 casos confirmados e 67.594 óbitos, com taxa de letalidade de 5,6\%. (Neto et al, 2020). 200 anos de Florence Nightinagale, desde o seu nascimento. Homenagem que em cenário internacional vem à tona para, talvez, testar a enfermagem com a pandemia da Covid-19.

Aplausos pelas janelas, pautada nas mídias, até de heróis os profissionais de enfermagem foram chamados. Mas de que adianta? A enfermagem pensou em comemorar o ano dedicado à sua existência, mas como comemorar quando os protagonistas da festa eram convocados a assumirem mais plantões aumentado pela carga de trabalho demandado pelo acometidos pela Covid-19? Perguntas e mais perguntas poderíamos fazer, mas os colegas passam pelas nossas mãos com água, pois cadê tempo para analisar com afinco, quando os profissionais de enfermagem se encontram cansados de corpo e alma, e mais, muitos sem condições adequadas de trabalhos expostos pelas mídias nacional e internacional. Previsões futurísticas apontavam para indícios de uma possível terceira guerra mundial, mediante aos aspectos políticos internacionais, mas o que tivemos/temos de enfrentar é uma pandemia, que na voz corrente é um pandemônio instalado pela COVID-19. Para tanto, efeitos na economia, nas relações internacionais e cultura, dentre outros, provocam instabilidade de diversas ordens potencializado pelo distanciamento social. Estes aspectos de precaução e prevenção trouxe consigo de forma potente a inovação tecnológica para tentar amenizar $\mathrm{o}$ afastamento das pessoas, causando agravos 
a saúde mental e nova etiqueta cultural dos cuidados.

As fake News com as pseudoinformações, bem como ocorreu na gripe espanhola não ficou/fica de fora do período pandêmico. Exemplo do dito, é que no Brasil, no banco de dados do Ministério da Saúde 70 registros foram encontrados no período de 29 de janeiro a 31 de março de 2020, que agrupadas tratam-se de discursos de autoridades na saúde (40), terapêuticas (17), medidas de prevenção (09), prognósticos da doença (02) e vacinação (Neto et al, 2020). A distinção de hoje para o passado é que a informação tem o poder de circulação muito mais rápida. Ao revisitamos o passado pelos registros deixados por Florence é possível identificar a preocupação, especialmente, com a lavagem das mãos, higiene corporal e ventilação do ambiente como lições deixadas por ela.

$\mathrm{Na}$ atualidade do século XXI, distintamente do século XIX, contamos com a substância do álcool gel e, por exemplo, os macacões de tayvek. O primeiro trata-se de inovação à base de combinação de substâncias químicas para os cuidados, criado por Lupe Hernandez na década de 1960 (Paiva, 2020) e o segundo oriundo da indústria têxtil, pela marca da Dupon, é um tecido não tecido com características próprias conhecido desde da década de 1970 (Pacce, 2020). Isto traz por efeito, mais produtos para compor o menu em prol da higiene, combate e prevenção contra a Covid-19.

Mesmo assim, mediante ao exposto dados divulgados pela monitorização da Unidade Johns Hopkins (Baltimore, EUA), em 21 de maio de 2020, registraram a mortalidade de 329.142 e casos suspeitos de 4.998.203 de pessoas que clamavam pela atenção no campo da saúde.

\section{CONSIDERAÇÕES FINAIS}

Pensar nessa perspectiva reflexiva, é entender que os cuidados higiênicos são fundamentais, seja na promoção, seja na prevenção à saúde. Atitude simples, mas complexa para algumas culturas mundiais, quando as políticas públicas carecem de investimento na vertente social, sanitária, econômica e cultural em prol de atender ao conceito central da Organização Mundial de Saúde, segundo sua concepção.

Enfim, pensar e viver o período pandêmico é também (re)apreender lições deixadas do passado e fazer o dever negligenciado no presente, porém advertido de tempos idos e se reinventar para o futuro do século do XXI que acreditamos ter começado agora. Isto implica em esperança de mundo melhor para as próximas gerações.

\section{REFERÊNCIAS}

Albuquerque Júnior, D. M. (2007). História: a arte de inventar o passado - ensaios de teoria da história. Bauru, São Paulo: Edusc.

Porto, F Costa, I. Z. K., Gomes, T. O, Correia, L. M., Carrilho, N. L. M., Neto, M. (2020). Em tempos da Covid-19: aplicações das lições deixadas por Florence Nightingale. Hist enferm Rev eletrônica, 11(Especial), 64-72.

Pacce, L. (2020, 13 de abril). A moda e a roupa de proteção usada por profissionais da saúde no combate ao Covid-19. [Vídeo]. Youtube. Recuperado de https://www.youtube.com/watch?v=3rXSfu oU2OU\& $\mathrm{t}=52 \mathrm{~s}$

Giovanetti, F. (2019, 16 de novembro). Por que somos tão obcecados com tipos de personalidade. Médio. Recuperado de https://medium.com/the-business-ofwellness/why-we-are-so-obsessed-with- 
personality-types-577450f9aee9

Figueiredo, N. M. A. (2020, 12 de maio). ENFERMAGEM entre a COVID 19 e a VIDA: a barreira VISÍVEL DO CUIDADO. Journal de Dados PPGENFBIO. Recuperado de

https://journaldedados.wordpress.com/2020 /05/12/12-de-maio-dia-internacional-deenfermagem/

Paiva, V. (2020). Uma mulher latina, estudante de enfermagem, inventou o álcool gel. Recuperado de https://www.hypeness.com.br/2020/03/uma -mulher-latina-estudante-de-enfermageminventou-o-alcool-gel/

Neto, M., Gomes, T. O., Porto, F. R., Rafael R. M. R., Fonseca M. H. S., Nascimento J. (2020). Fake News no cenário da pandemia de Covid-19. Cogitare enferm. 25.

Molière. J. B. P. (2003). $O$ doente imaginário. $3^{\mathrm{a}}$ Ed. São Paulo: Martin ClareT. 